\title{
Boron Neutron Capture Therapy for Malignant Brain Tumors
}

\section{$\operatorname{AUTHOR}(\mathrm{S})$ :}

MIYATAKE, Shin-Ichi; KAWABATA, Shinji; HIRAMATSU, Ryo; KUROIWA, Toshihiko; SUZUKI, Minoru; KONDO, Natsuko; ONO, Koji

\section{CITATION:}

MIYATAKE, Shin-Ichi ...[et al]. Boron Neutron Capture Therapy for

Malignant Brain Tumors. Neurologia medico-chirurgica 2016, 56(7): 361371

\section{ISSUE DATE:}

2016-07

URL:

http://hdl.handle.net/2433/226821

\section{RIGHT:}

This article is applied Creative Commons Attribution Non-CommercialNoDerivs License (CC BY-NC-ND) by the publisher. 


\title{
Boron Neutron Capture Therapy for Malignant Brain Tumors
}

\author{
Shin-Ichi MiYATAKE, ${ }^{1,2^{*}}$ Shinji KAWABATA, ${ }^{2}$ Ryo HIRAMATSU, ${ }^{2}$ \\ Toshihiko KUROIWA, ${ }^{2}$ Minoru SuZUKI, ${ }^{3}$ Natsuko KONDO, ${ }^{3}$ and Koji ONO ${ }^{3}$ \\ ${ }^{1}$ Cancer Center, Osaka Medical College, Takatsuki, Osaka; \\ ${ }^{2}$ Department of Neurosurgery, Osaka Medical College, Takatsuki, Osaka; \\ ${ }^{3}$ Particle Radiation Oncology Research Center, Kyoto University Research, \\ Reactor Institute, Kumatori, Osaka
}

\begin{abstract}
Boron neutron capture therapy (BNCT) is a biochemically targeted radiotherapy based on the nuclear capture and fission reactions that occur when non-radioactive boron-10, which is a constituent of natural elemental boron, is irradiated with low energy thermal neutrons to yield high linear energy transfer alpha particles and recoiling lithium-7 nuclei. Therefore, BNCT enables the application of a high dose of particle radiation selectively to tumor cells in which boron-10 compound has been accumulated. We applied BNCT using nuclear reactors for 167 cases of malignant brain tumors, including recurrent malignant gliomas, newly diagnosed malignant gliomas, and recurrent high-grade meningiomas from January 2002 to May 2014. Here, we review the principle and history of BNCT. In addition, we introduce fluoride18-labeled boronophenylalanine positron emission tomography and the clinical results of BNCT for the above-mentioned malignant brain tumors. Finally, we discuss the recent development of accelerators producing epithermal neutron beams. This development could provide an alternative to the current use of specially modified nuclear reactors as a neutron source, and could allow BNCT to be performed in a hospital setting.
\end{abstract}

Key words: boron neutron capture therapy, malignant glioma, glioblastoma, high-grade meningioma, positron emission tomography

\section{Introduction and Principle of Boron Neutron Capture Therapy (BNCT)}

The BNCT in theory provides a way to selectively destroy malignant cells and spare normal cells. BNCT requires two components, i.e., a neutron and a boron-carrier. Sir James Chadwick discovered neutron in 1932 and was awarded the 1935 Nobel Prize in Physics for his discovery. ${ }^{1)}$ A mere 4 years later, Locher introduced the concept of BNCT. ${ }^{2}$ BNCT is based on the nuclear capture and fission reactions that occur when boron-10 $\left({ }^{10} \mathrm{~B}\right)$, which is a nonradioactive constituent of natural elemental boron, is irradiated with low-energy thermal neutrons to yield high linear energy transfer (LET) alpha particles $\left({ }^{4} \mathrm{He}\right)$ and recoiling lithium-7 $\left({ }^{7} \mathrm{Li}\right)$ nuclei.

In order for BNCT to be successful, a sufficient amount of ${ }^{10} \mathrm{~B}$ must be selectively delivered to the tumor

Received November 27, 2015; Accepted February 27, 2016 cells $\left(\sim 20 \mu \mathrm{g} / \mathrm{g}\right.$ weight or $\sim 10^{9}$ atoms/cell) with good contrast of accumulation to the surrounding normal cells, and a sufficient number of thermal neutrons must be absorbed by the tumor cells to sustain lethal damage from the ${ }^{10} \mathrm{~B}(\mathrm{n}, \alpha)^{7} \mathrm{Li}$ capture reaction. Since the high LET particles have limited path lengths in tissue $(5-9 \mu \mathrm{m})$, the destructive effects of these high LET particles are limited to boron-containing cells.

The principle of BNCT is shown in Fig. 1. In this figure, malignant gliomas in the brain are the presumed target. One characteristic of this type of tumor is that it infiltrates the surrounding normal brain. For this reason, care should be taken that the tumor cells selectively accumulate the ${ }^{10} \mathrm{~B}$ atoms rather than the normal cells. This selective accumulation is achieved by the nature of the ${ }^{10} \mathrm{~B}$-containing compounds themselves, and is discussed in detail in the next section. After the ${ }^{10} \mathrm{~B}$-containing compounds are accumulated in the tumor cells, the tumor cells are irradiated with non-hazardous low-energy 

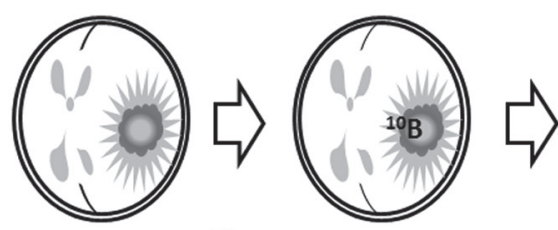

${ }^{10} \mathrm{~B}$ administration

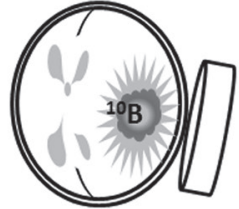

neutron irradiation

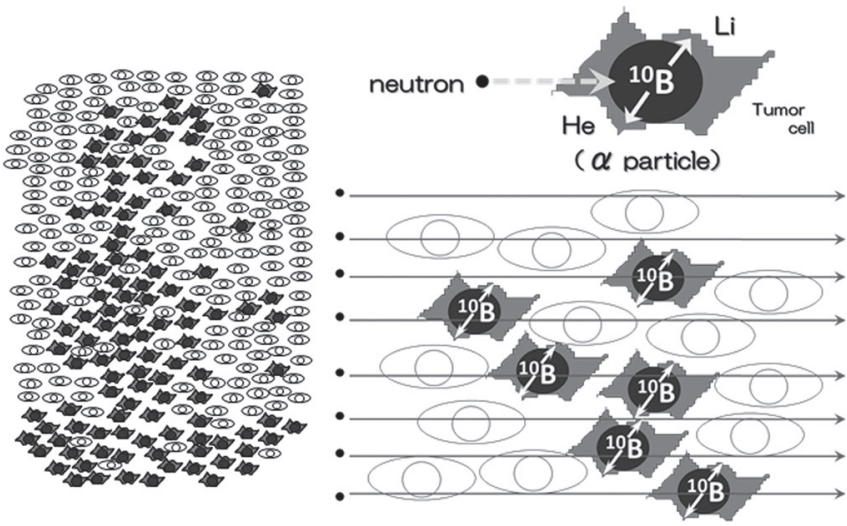

thermal neutrons. During this process, it is not necessary to aim the neutron irradiation exclusively at the tumor cells. High LET particles will destroy only ${ }^{10} \mathrm{~B}$-containing cells and preserve the normal surrounding cells, as shown in Fig. 1.

Clinical interest in BNCT has focused primarily on high-grade gliomas, ${ }^{3-5)}$ and more recently on patients with recurrent tumors of the head and neck region who have failed conventional therapy. ${ }^{6-9)}$ In 1950s in the USA, Farr et al. performed the first clinical trial of BNCT for malignant gliomas. ${ }^{10,11)}$ Unfortunately the trial was unsuccessful due to the poor accumulation of boron compound in tumor tissues and a lack of neutron penetration. Since BNCT is primarily a biochemically rather than a physically targeted type of radiation treatment, the potential exists to destroy tumor cells dispersed in normal brain tissue, if sufficient amounts of ${ }^{10} \mathrm{~B}$ and thermal neutrons are delivered to the target volume, as described above. In this review article, we will provide an update on BNCT, specifically as it relates to the treatment of recurrent and newly diagnosed high-grade gliomas, and recurrent high-grade meningiomas, and chiefly based on our experiences. We will also discuss accelerator-based BNCT and other recent developments.

\section{Selective Accumulation of Boron Compounds and Positron Emission Tomography (PET) Imaging}

The selective tumor cell destruction in BNCT is achieved by selective accumulation of ${ }^{10} \mathrm{~B}$ atoms in tumor cells, which is dependent on the characteristics of the boron-delivery agents. The most important

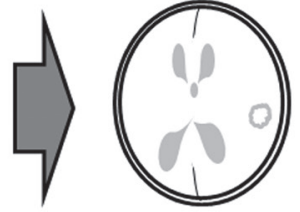

1 The principle of boron neutron capture therapy (BNCT). BNCT is a binary approach. A boron-10 $\left({ }^{10} \mathrm{~B}\right)$-labeled compound is administered that delivers high concentrations of ${ }^{10} \mathrm{~B}$ to the target tumor relative to surrounding normal tissues. This is followed by irradiation with thermal neutrons or epithermal neutrons that become thermalized at depth in tissues. The short range (5-9 micrometers) of high LET alpha and ${ }^{7} \mathrm{Li}$ particles released from the ${ }^{10} \mathrm{~B}\left(\mathrm{n}\right.$, alpha) ${ }^{7} \mathrm{Li}$ neutron capture reaction realizes tumor-selective killing without damage to adjacent normal brain tissue.

requirements for a successful boron-delivery agent are: (1) low systemic toxicity and low normal tissue uptake with high tumor uptake and concomitant high tumor: brain contrast ( $>3-4: 1)$; (2) tumor concentrations of at least $\sim 20 \mu \mathrm{g}{ }^{10} \mathrm{~B} / \mathrm{g}$ tumor; and (3) rapid clearance from the blood and normal tissues and persistence in tumors during BNCT. Because of these stringent requirements, there are only two boron delivery agents in clinical use: the polyhedral boron anion, sodium mercaptoundecahydro-closododecaborate $\left(\mathrm{Na}_{2} \mathrm{~B}_{12} \mathrm{H}_{11} \mathrm{SH}\right)$, commonly known as sodium borocaptate $\left(\mathrm{BSH}^{12}\right)$; and the boron-containing amino acid (L)-4-dihydroxyborylphenylalanine, known as boronophenylalanine (BPA). Structural diagrams of both compounds are shown in Fig. 2.

Each of these compounds reaches or accumulates in different subpopulations of tumor cells in a different fashion. ${ }^{13)} \mathrm{BSH}$ is not delivered into the normal brain through the blood-brain barrier, and thus the concentration of this compound in tumor tissue is related to both the tumor vasculature and

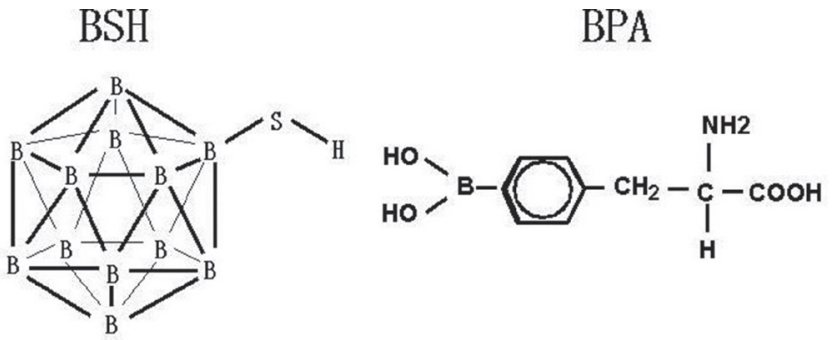

Fig. 2 Structural diagrams of sodium borocaptate (BSH) and boronophenylalanine (BPA). BSH is a macromolecule. BPA is boronated-phenylalanine, one of the essential amino acids. 

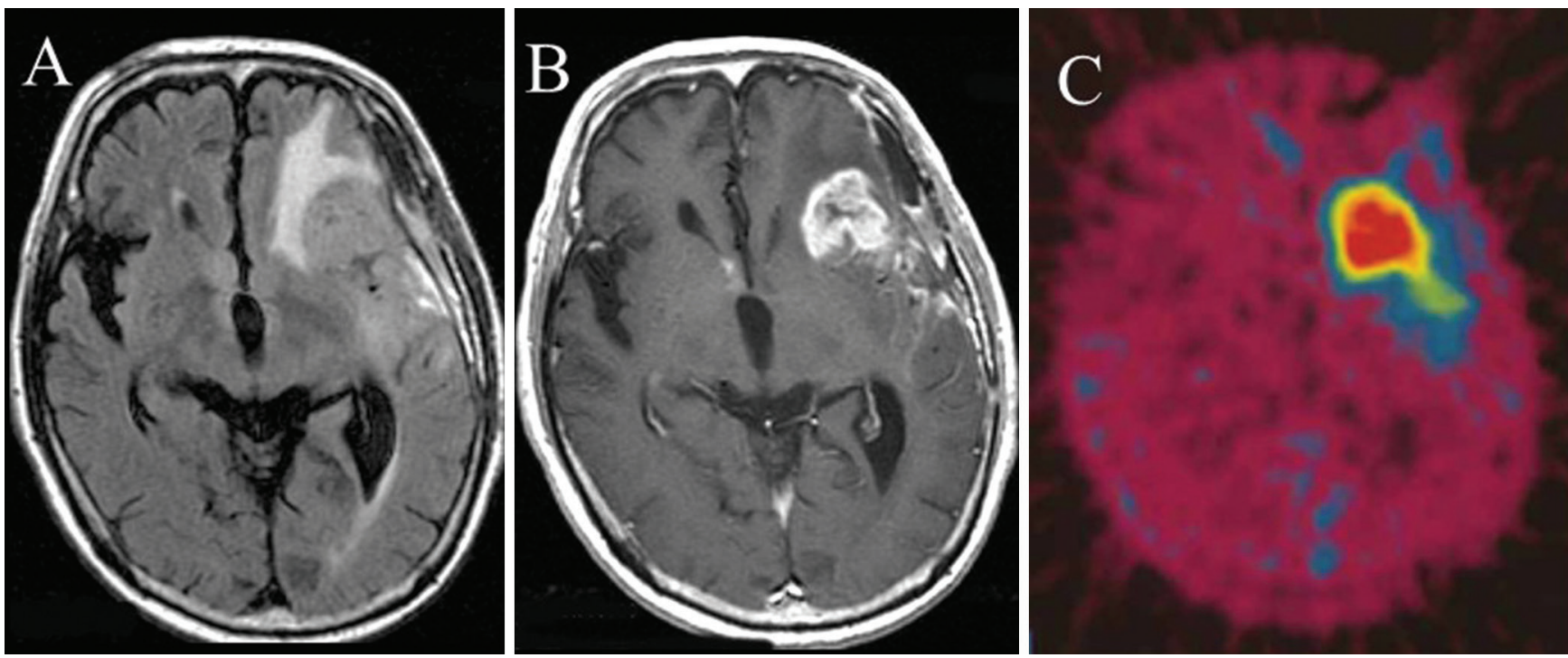

Fig. 3 Fluid-attenuated inversion recovery (FLAIR) and contrast-enhanced $T_{1}$-weighted magnetic resonance imaging (MRI) of a representative glioblastoma patient and ${ }^{18} \mathrm{~F}$-labeled boronophenylalanine-positron emission tomography (BPA-PET) image after initial debulking surgery. The patients received ${ }^{18} \mathrm{~F}$-BPA-PET to assess the distribution of BPA and to estimate the boron concentration in tumors before boron neutron capture therapy (BNCT) without direct determination of boron concentration in the tumor. A: FLAIR and B: Gd-enhanced $\mathrm{T}_{1}$-weighted MRI. C: ${ }^{18} \mathrm{~F}$-BPA-PET image. All images were obtained after initial debulking surgery and prior to BNCT. The lesion-to-normal $(\mathrm{L} / \mathrm{N})$ brain ratio of the enhanced tumor was 7.8 in this case. Note that even the periphery of the main mass, that is, the infiltrative portion of the tumor, showed BPA uptake. The L/N ratio of BPA uptake was estimated from this study and was then used for the dose planning. ${ }^{18} \mathrm{~F}-\mathrm{BPA}$-PET provided an accurate estimate of the accumulation and distribution of BPA as previously reported. ${ }^{61,62)}$

its concentration in the blood. BPA accumulates preferentially into the actively proliferating subpopulation via the augmented expression of amino acid transporters on tumor cells. However, some of this compound inevitably accumulates in normal tissue. No apparent adverse effect has been observed by BSH administration. As a sole adverse effect of intravenous BPA administration, re-crystallization of this agent in the urinary tract should be mentioned. This might be followed by transient high-grade fever. This adverse effect can be avoided by appropriate hydration after neutron irradiation.

The selective destruction of glioblastoma (GBM) cells in the presence of normal cells represents even greater challenge than malignancies at other anatomic sites, since high-grade gliomas are highly infiltrative into the normal brain, histologically complex, and heterogeneous in their cellular composition.

To ensure the selective accumulation of BPA and to make a dose-simulation prior to neutron irradiation, we used ${ }^{18} \mathrm{~F}$-BPA-PET. This readily gave us an accurate BPA accumulation and distribution before irradiation, i.e., without craniotomy. ${ }^{14-16)}$ A representative ${ }^{18} \mathrm{~F}$-BPA-PET image is depicted in Fig. 3. The lesion-to-normal $(\mathrm{L} / \mathrm{N})$ brain ratio of the enhanced tumor was 7.8 in this case. Note that even the periphery of the main mass, that is, the infiltrative portion of the tumor without contrast enhancement, showed BPA uptake. These results were used to estimate the L/N ratio of BPA uptake, which in turn was used for dose planning. The PET image provides clear evidence of tumor cell-selective destruction by BNCT using BPA.

\section{BNCT for Recurrent Malignant Gliomas}

Initially we applied BNCT for recurrent malignant gliomas. In clinical usage, either BPA alone or in combination with $\mathrm{BSH}$ has generally been used for BNCT of recurrent malignant gliomas. On neuroimages from contrast-enhanced computed tomography (CT) or magnetic resonance imaging (MRI), marked early shrinkage of the enhanced lesions or perifocal edema was evident in these initial studies. ${ }^{17,18)}$ More than $50 \%$ of the contrast-enhanced volumes disappeared in 8 out of the 12 patients during the follow-up period. ${ }^{18)}$ To overcome the weak points of BNCT as performed in the 1950s and to improve the clinical results, we used an epithermal neutron beam instead of a thermal neutron beam, since the neutron flux by the latter was often insufficient, especially in the deeper parts of the brain. 
In addition, we used BSH and BPA simultaneously, a method reported elsewhere as modified BNCT. ${ }^{18)}$

Fig. 4 shows representative MRI changes in a case of recurrent malignant glioma treated by BNCT using BPA as the sole boron compound. The original histology was anaplastic oligo-astrocytoma and the mass recurred after chemo-irradiation using standard chemo-radiotherapy composed of X-ray treatment (XRT) and temozolomide (TMZ). BNCT was applied for this patient according to our recent protocol for recurrent malignant gliomas and meningiomas. ${ }^{19)}$ Briefly, only BPA was administered over a 2-hr period (200 $\mathrm{mg} / \mathrm{kg} / \mathrm{hr}$ ) just prior to and during the neutron irradiation $(100 \mathrm{mg} / \mathrm{kg} / \mathrm{hr})$. Based on the PET-based simulation described above, we chose a neutron irradiation time that would keep the peak brain dose below 12.0 Gy-Eq (gray-equivalent). Here, Gy-Eq corresponds to the biologically equivalent $\mathrm{X}$-ray dose that would have equivalent effects on tumors and on the normal brain. Fig. 4 shows the continuous shrinkage of the mass over 1 year without any evidence of recurrence on MRI.

Next we assessed the survival benefit of treating recurrent malignant gliomas by BNCT. ${ }^{20)}$ Since the approval of on-label use of bevacizumab for malignant glioma in Japan, this agent has been used in many cases of newly diagnosed or recurrent malignant glioma. In addition, a tumor treatment field (TTF)device has been developed for use in the treatment of GBMs. Unfortunately, however, no standard treatment has yet been established for recurrent malignant gliomas. Therefore it was difficult to evaluate the survival benefit of BNCT for recurrent malignant gliomas. To address this problem, we evaluated the survival benefit in patients classified into two groups, low- and high-risk recurrent malignant gliomas, by adopting the recursive partitioning analysis (RPA) classification for recurrent malignant glioma advocated by Carson et al. This classification system, which was presented in a 2007 article in the Journal of

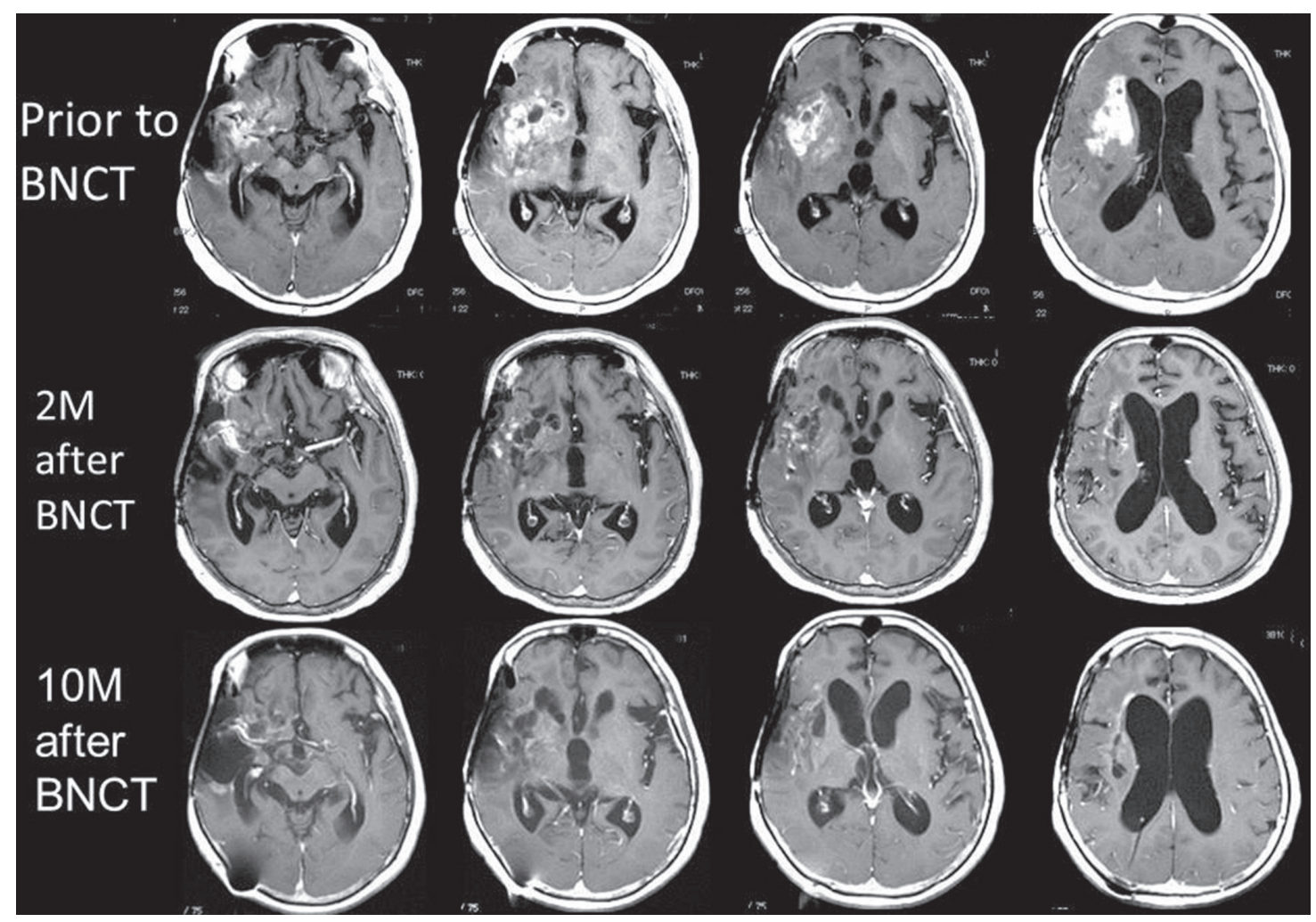

Fig. 4 Representative MRI changes in a case of recurrent malignant gliomas treated by BNCT. The patient underwent a craniotomy and the histological analysis indicated anaplastic oligo-astrocytoma. She received chemoirradiation with several chemotherapeutic regimens, including procarbazine, lomustine, vincristine (PCV) and TMZ. Unfortunately, the mass recurred with aggravation of the left hemiparesis. RPA classification for recurrent malignant gliomas was judged as class 3 , and therefore the estimated median survival time at recurrence was 3.8 months. The MRI prior to BNCT showed irregularly enhanced mass infiltrates from the right frontal and temporal lobes into the basal ganglia. After BNCT, the mass shrunk rapidly and constantly. One year after BNCT, the patient is well without any chemotherapy. BNCT: boron neutron capture therapy, MRI: magnetic resonance imaging, PCV: procarbazine, lomustine, vincristine, RPA: recursive partitioning analysis, TMZ: temozolomide. 
Clinical Oncology, was based on the results of 10 recent protocols of phase- 1 and -2 trials applied by the New Approaches to Brain Tumor Therapy CNS Consortium for recurrent malignant glioma. ${ }^{21}$ When we published our initial results of BNCT for recurrent malignant glioma, the survival data were analyzed using 22 consecutive cases of recurrent malignant gliomas treated by BNCT from 2002 to 2007. Here, cases without GBM based on initial histology and with KPS $\leq 70 \%$ were assigned to RPA class 3, while those with GBM based on initial histology, age $\geq 50$, and steroid use were classified as RPA class 7. The median survival times (MSTs) after BNCT for all patients and for GBM as on-study histology at recurrence were 10.8 months ( $\mathrm{n}=22$; 95\% CI, 7.3-12.8 months) and 9.6 months ( $\mathrm{n}=19$; 95\% CI, 6.9-11.4 months) in our series, respectively. The MST for high-risk RPA classes (class $3+7$ ) was 9.1 months ( $\mathrm{n}=11$; 95\% CI, 4.4-11.0 months). By contrast, the original data of Carson et al. showed that the MST of the same RPA classes was only 4.4 months ( $\mathrm{n}=129 ; 95 \%$ CI, 3.6-5.4 months). BNCT showed a marked survival benefit for recurrent malignant glioma, especially in the high-risk group. ${ }^{20)}$ Moreover, the median target volume on contrast MRI in our series was $42 \mathrm{ml}$, which is too large for treatment by stereotactic radiosurgery. In our data published in $J$ Neuro-Oncol in $2009^{20)}$ out of 22 cases of recurrent malignant gliomas treated by BNCT, we lost 5, 10, 1 and 3 cases due to local tumor progression, CSF dissemination, a combination of both, and uncontrollable brain radiation necrosis, respectively.

The biggest drawbacks with BNCT for recurrent malignant gliomas are the occurrence of brain radiation necrosis and symptomatic pseudoprogression. Most recurrent malignant glioma cases have already received nearly 60 Gy XRT prior to re-irradiation by BNCT. Even with tumor-selective particle radiation BNCT, brain radiation necrosis. and symptomatic pseudoprogression may develop. Occasionally brain radiation necrosis causes severe neurological deficits and sometimes it endangers the patient's life. The key molecule in this pathology is vascular endothelial growth factor (VEGF). Bevacizumab, an anti-VEGF antibody, has recently been used for the treatment of symptomatic brain radiation necrosis. ${ }^{22,23)}$ We have used bevacizumab in an attempt to control the symptomatic brain radiation necrosis and the symptomatic pseudoprogression encountered after BNCT for recurrent malignant gliomas with promising results. ${ }^{24-26)}$ Therefore, BNCT in combination with bevacizumab should both prolong the survival and improve the quality of life of recurrent malignant glioma patients. Here we introduce a representative case of brain radiation necrosis caused by BNCT and successfully treated with bevacizumab (Fig. 5).

\section{BNCT for Newly Diagnosed Malignant Gliomas}

Hatanaka and his colleagues reported a good result of BNCT for newly diagnosed malignant gliomas between 1987 and 1994. ${ }^{27)}$ However, Laramore et al. $^{28)}$ analyzed the survival data of a subset of 12 patients who had been treated by Hatanaka et al. and concluded that there were no differences in their survival times compared with the RTOGRPA classifications. ${ }^{29)}$

Several clinical studies of BNCT for newly diagnosed malignant gliomas ${ }^{30-33)}$ were reported in the first decade of the 2000s in Europe and in the USA. In each of the studies, the MST was approximately 13 months. Although these survival times were similar to those obtained with surgery followed by XRT, no firm conclusions can be made as to whether the clinical results of BNCT are equivalent or superior to those of XRT.

On the other hand, after the confirmation of the effectiveness of BNCT for recurrent malignant glioma, we applied BNCT for newly diagnosed malignant gliomas, most of which were GBM. We have carried out several clinical studies in which BPA alone or in combination with BSH was administered for treatment of patients with primary, surgically resected malignant glioma. ${ }^{34)}$ In patients with newly diagnosed GBMs, favorable responses were seen using BNCT with BPA and BSH either with or without an XRT boost, especially in high-risk groups. The MST of patients treated with this regimen (BNCT with X-ray boost) was 23.5 months compared to 15.6 months [95\% confidence interval (CI): 12.2-23.9 months] after diagnosis for patients who had surgery followed by BNCT alone. This was significantly longer than the MST of 10.3 months for the historical controls ( $\mathrm{n}=$ 27) at Osaka Medical College who had undergone surgical resection followed by XRT and chemotherapy with nitrosourea [mainly nimustine (ACNU)], as shown in Fig. $6{ }^{35)}$ Note that for these cases TMZ was not used.

Similarly, Yamamoto et al. have reported improved survival by combining BNCT with a photon boost. ${ }^{36)}$ Based on these experiences, we recently completed a multicenter phase 2 Japanese clinical trial to evaluate BNCT in combination with TMZ and an XRT boost (Osaka-TRIBRAIN 0902, NCT00974987) for newly diagnosed GBM. We are currently opening the results of this clinical trial and hope to report on our findings in the near future. 


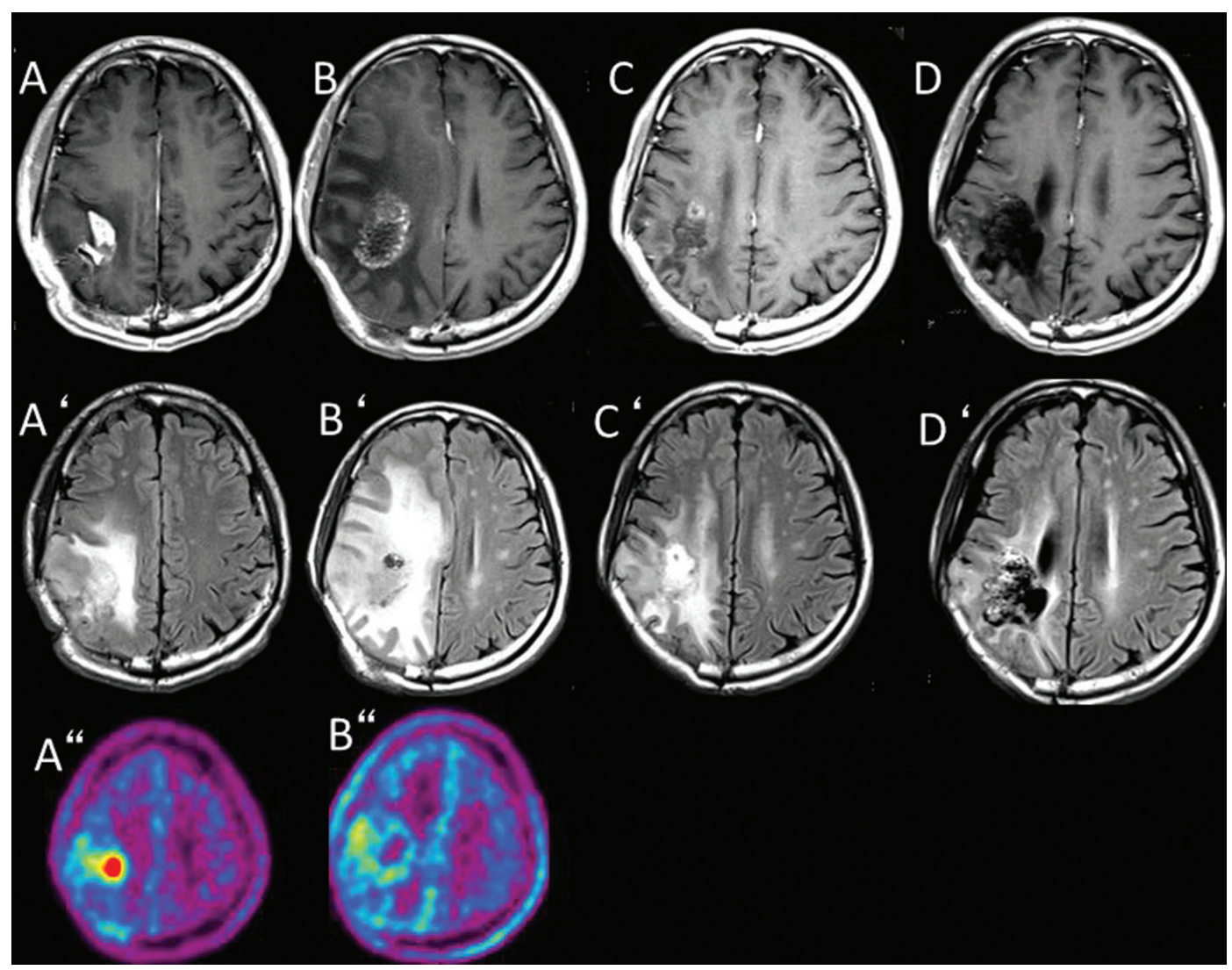

Fig. 5 A representative case of brain radiation necrosis caused by BNCT and treated with bevacizumab successfully. The right parietal GBM recurred after standard chemo-radiotherapy. The F-BPA-PET image showed marked tracer uptake in the right parietal region with a 3.8 lesion-to-normal $(\mathrm{L} / \mathrm{N})$ brain ratio of the tracer, indicating that the lesion was a recurrent GBM. The patient was treated with BNCT. Periodic MRIs showed gradual enlargement of both the enhanced lesion and perifocal edema, whereas ${ }^{18} \mathrm{~F}-\mathrm{BPA}$-PET showed a gradual decrease of the tracer uptake. The final L/N ratio, 13 months after BNCT, was 2.3. This $\mathrm{L} / \mathrm{N}$ ratio and the simultaneous MRI suggested that the lesion was brain radiation necrosis. The patient was not able to continue his work as a cook, and we decided to begin intravenous bevacizumab treatment biweekly $(5 \mathrm{mg} / \mathrm{kg})$. After four treatments, MRI showed marked improvement in the perifocal edema and left hemiparesis. The patient is now doing well and has resumed his work as a cook, 44 months after the BNCT, without tumor progression or recurrence of the radiation necrosis. A, $A^{\prime}$ and A": Gd-enhanced $T_{1}$-weighted and FLAIR MRI and ${ }^{18} \mathrm{~F}$-BPA-PET imaging taken just prior to BNCT. B, B' and B": Gd-enhanced $T_{1}$-weighted and FLAIR MRI and ${ }^{18}$ F-BPA-PET imaging taken 13 months after BNCT. From $B$ ", we judged this worsening on MRI as brain radiation necrosis. C, C': Gd-enhanced $T_{1}$-weighted and FLAIR MRI taken 15 months after BNCT and 2 months after the initiation of bevacizumab treatment. D, D': Gd-enhanced $\mathrm{T}_{1}$-weighted and FLAIR MRI taken 44 months after BNCT with bevacizumab treatments. BNCT: boron neutron capture therapy, BPA-PET: boronophenylalanine-positron emission tomography, FLAIR: fluid-attenuated inversion recovery, GBM: glioblastoma, L/N: lesion-to-normal, MRI: magnetic resonance imaging.

\section{BNCT for High-grade Meningiomas}

The management of high-grade meningioma, especially malignant meningioma, is very difficult. In a large series of patients with this disease, the 5 -year recurrence rate of high-grade meningioma was reported as $78-84 \%{ }^{37)}$ The MST of patients has been reported as 6.89 years; late mortality due to recurrence after the initial surgery has been reported at $69 \%{ }^{38)}$ Although some treatments for recurrent high-grade meningioma have been reported, including chemotherapeutic regimens, no standard treatment has yet been established. ${ }^{39)}$

Since 2005, we have applied BNCT for cases of high-grade meningioma recurrent after or refractory to any intensive treatment modality. ${ }^{40,41)}$ To date we have treated 32 consecutive cases of high-grade meningiomas with BNCT. Twenty cases were followed up for more than 4 years and the MSTs after BNCT and diagnosis were 14.1 (95\% CI: 8.6-40.4) and 45.7 months (95\% CI: $32.4-70.7$ ), respectively. ${ }^{19)}$ A representative case is shown in Fig. 7. Like the 
case shown in this figure, all cases responded well to BNCT and showed good shrinkage of the mass after BNCT.

However, many cases were lost even after BNCT. Out of 20 cases of high-grade meningioma treated

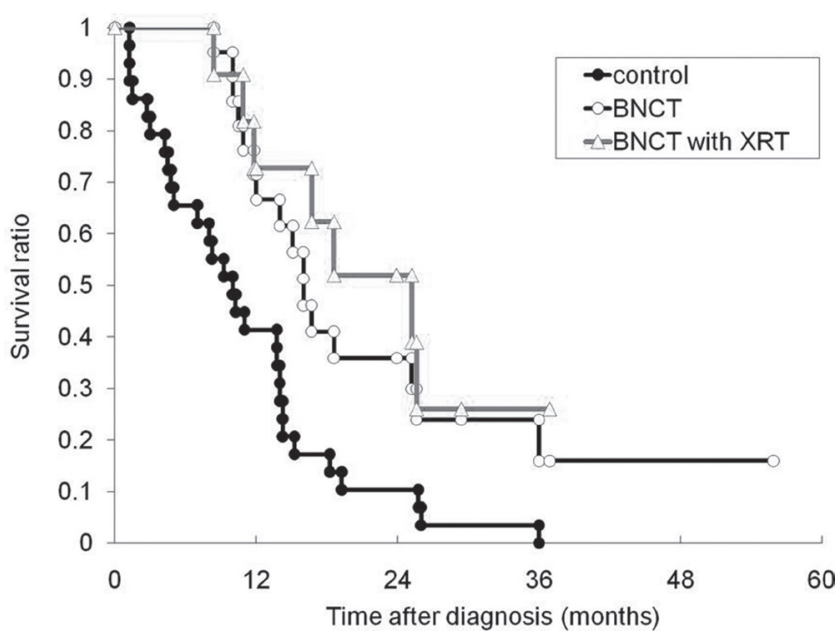

Fig. 6 Kaplan-Meier survival curves of newly diagnosed glioblastoma patients treated with BNCT. The closed circles represent the survival times of our institutional historical controls (surgical removal, XRT, and chemotherapy, mainly ACNU-based) $(n=27)$ and show an MST of 10.3 months. The open circles represent the survival times of the patients treated with BNCT (protocols 1 plus 2, $n=21$ ), and show an MST of 15.6 months (logrank test, $p=0.0035$ ). The open triangles represent the survival times of the patients treated with protocol 2, $\mathrm{n}=11$, and show an MST of 23.5 months. In protocol 1 , the patients received BNCT alone as radiotherapy and in protocol 2, patients received BNCT followed by XRT. This data was taken from our previous study. ${ }^{34)}$ BNCT: boron neutron capture therapy, MST: median survival time, XRT: X-ray treatment. by BNCT, we lost 13 cases, 2 from local tumor progression with radiation necrosis, 1 from simple local tumor progression, 4 from systemic metastasis, 1 from intracranial distant recurrence outside the irradiation field, 3 from CSF dissemination, and 2 from other diseases. ${ }^{20)}$ These problems must be overcome. ${ }^{19)}$

\section{From Reactor to Accelerator}

Before 2012, all BNCT clinical irradiations were carried out at reactor neutron sources. As described above, BNCT is very effective for recurrent malignant gliomas and high-grade meningiomas. The biggest restriction of BNCT for universal and standard use as radiation therapy not only for malignant brain tumors but also for malignancies at other organs is the use of nuclear reactors. More than eight such facilities have been constructed for clinical use in the USA, Argentina, Europe, and Asia. However, nuclear reactors require a vast amount of land and very large structures. In addition, they run the risk of contamination by radioactivity. In the disastrous 2011 Tohoku earthquake and tsunami in northern Japan, one of the two nuclear reactors that could be used for BNCT was shut down. In addition, as this manuscript is being prepared, another Kyoto University Research Reactor has been ordered to be closed beginning in June 2014 for a thorough check and maintenance.

Another potential source of neutrons is the accelerator-based neutron sources currently being developed as neutron sources in hospital settings. Accelerator sources are expected to be much easier to license in a hospital setting than nuclear reactors. Proponents of accelerator-based neutron sources also believe that they could be more compact and less expensive
A

B

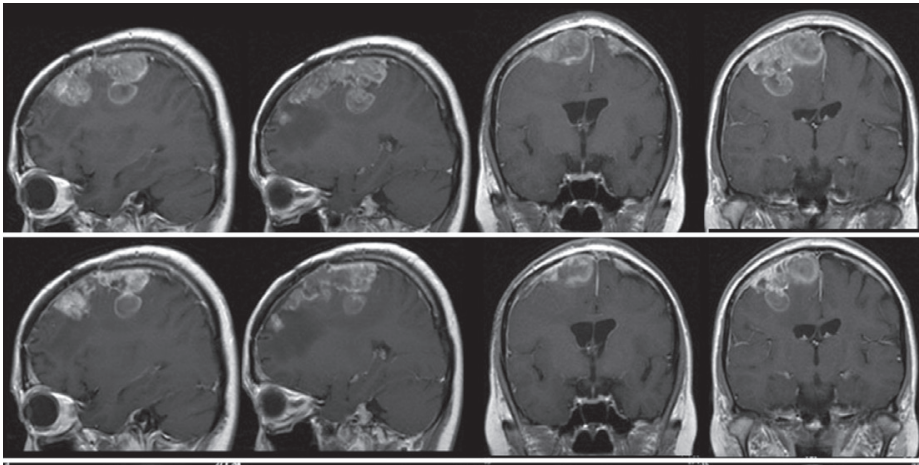

C

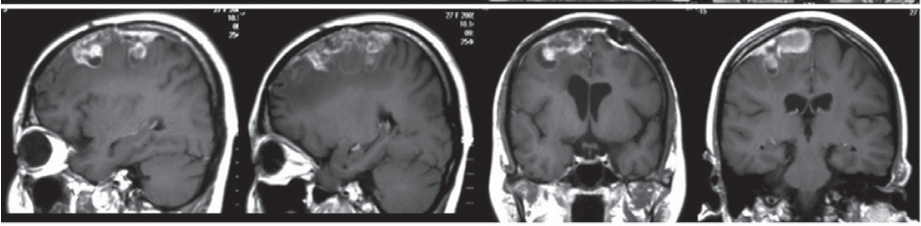

Fig. 7 Representative treatment effects of BNCT on high-grade meningiomas. A 25-year-old woman who had a history of repetitive recurrence of rhabdoid meningioma (WHO grade 3) even after several surgeries and SRSs. Serial contrast-enhanced axial, coronal, and sagittal magnetic resonance images demonstrated that a right frontal tumor, which had rapidly re-grown after the last GKS, was reduced gradually in 4 months after BNCT. Prior to BNCT, she manifested left hemiparesis and could mobilize only with a wheelchair, whereas she began to walk within a week after BNCT. A: One week prior to BNCT; B: Two weeks after BNCT; C: Four months after BNCT. BNCT: boron neutron capture therapy, GKS: gamma knife surgery, SRS: stereotactic radiosurgery, Sumitomo Heavy Industries (Shinagawa-ku, Tokyo, Japan). WHO: World Health Organization. 

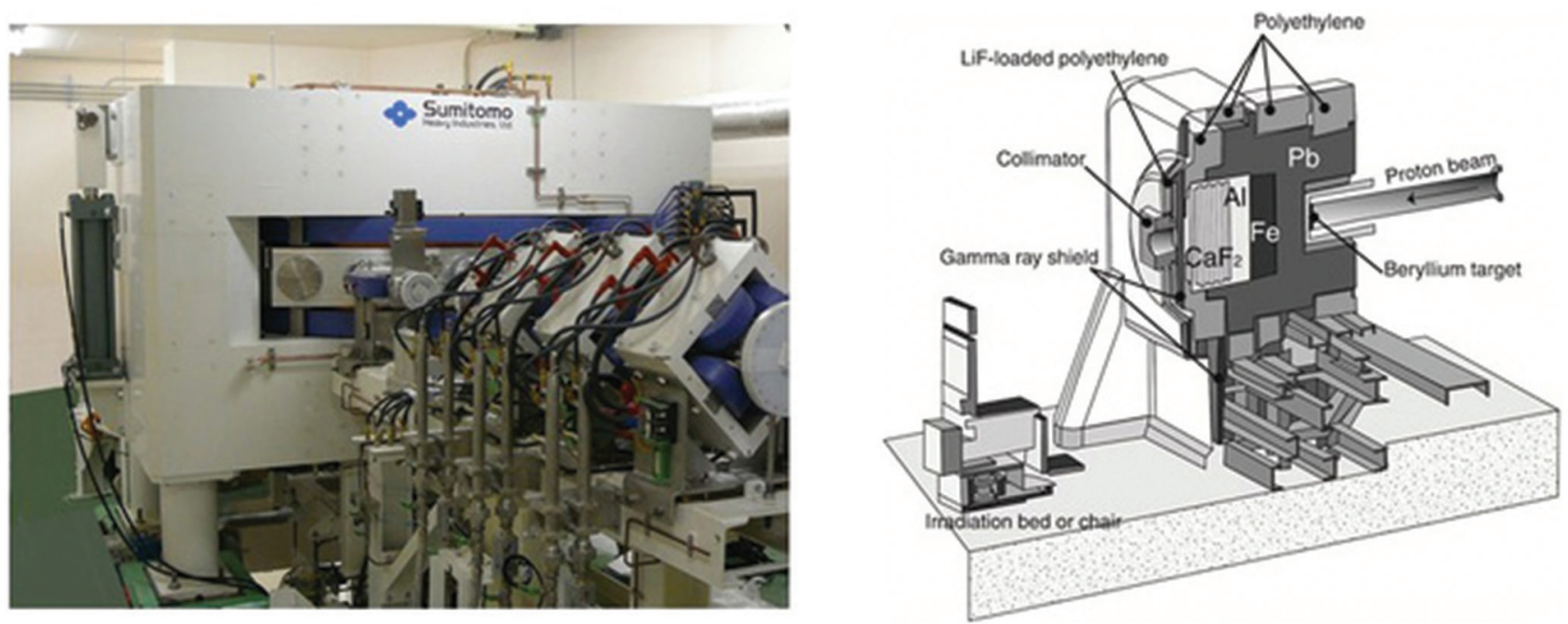

Fig. 8 A photograph of a cyclotron-based accelerator for neutron generation and an illustration of an irradiation room including a beryllium target, collimator, and irradiation bed or chair. By courtesy of Sumitomo Heavy Industries, Ltd., Shinagawa-ku, Tokyo, Japan.

than comparable reactor sources. However, generally speaking, their low intensity of neutrons, compared to reactors, has been a problem. It has been necessary to increase the intensity of the neutron supply by more than an order of magnitude, if accelerators are to be competitive with reactor sources for clinical BNCT. This would require that the accelerator current and target heat load also be increased by more than an order of magnitude over that achievable with the currently available technology.

For practical use, a small accelerator-based neutron source has been produced in Japan by Sumitomo Heavy Industries, Ltd., in which a cyclotron is used to generate the protons (cyclotron-based epithermal neutron source). ${ }^{42,43)}$ Here, we introduce this cyclotronbased epithermal neutron source system in Fig. 8. In addition, we have finished a phase 1 clinical trial for patients with recurrent malignant gliomas that was the first in the world to use a cyclotron-based epithermal neutron source system. This was followed by a trial in patients with recurrent head and neck cancers. We are now starting a phase 2 clinical trial for recurrent malignant glioma using a cyclotron-based epithermal neutron source. Hopefully all clinical BNCT irradiation will be replaced with accelerator-based neutron sources from reactor-based BNCT in the next decade.

\section{Future Prospects}

As discussed above, the recent decade has been the era of the development of accelerator-based neutron sources for BNCT. On the other hand, many researchers have conducted much successful clinical work using BSH and BPA as boron carriers in BNCT, as mentioned above. In the past decades, many boron carriers have been tested preclinically, including dodecaborate cluster lipids and cholesterol derivatives, ${ }^{44)}$ boron-containing liposomes, ${ }^{45,46)}$ boronated DNA intercalators, ${ }^{47)}$ transferrin-polyethylene glycol liposomes, ${ }^{48,49)}$ boronated porphyrins, ${ }^{50-52)}$ boronated epidermal growth factor (EGF), antiepidermal growth factor receptor (EGFR), vascular endothelial growth factor receptor (VEGFR) monoclonal antibodies, ${ }^{53-59)}$ BSH fused cell-penetrating peptide, ${ }^{60)}$ and so on. However, no boron carriers have surpassed BSH and BPA. At this stage, for a boron-carrier to be considered superior, it will need to achieve a definitive improvement in the success of BNCT. Following this metric, we must seek an ideal boron carrier with greater efficacy than BSH and BPA in the coming decades.

\section{Conflicts of Interest Disclosure}

There is no conflict of interest to disclose for any of the authors.

\section{References}

1) Chadwick J: The existence of a neutron. Proc $R$ Soc London A 136: 692-708, 1932

2) Locher GL: Biological effects and therapeutic possibilities of neutrons. Am J Roentgenol Radium Ther 36: 1-13, 1936

3) Barth RF: A critical assessment of boron neutron capture therapy: an overview. J Neurooncol 62: 1-5, 2003 
4) Barth RF, Coderre JA, Vicente MG, Blue TE: Boron neutron capture therapy of cancer: current status and future prospects. Clin Cancer Res 11: 3987-4002, 2005

5) Slatkin DN: A history of boron neutron capture therapy of brain tumours. Postulation of a brain radiation dose tolerance limit. Brain 114 (Pt 4):1609-1629, 1991

6) Aihara T, Hiratsuka J, Morita N, Uno M, Sakurai Y, Maruhashi A, Ono K, Harada T: First clinical case of boron neutron capture therapy for head and neck malignancies using 18F-BPA PET. Head Neck 28: 850-855, 2006

7) Kankaanranta L, Seppälä T, Koivunoro H, Saarilahti K, Atula T, Collan J, Salli E, Kortesniemi M, UusiSimola J, Välimäki P, Mäkitie A, Seppänen M, Minn H, Revitzer H, Kouri M, Kotiluoto P, Seren T, Auterinen I, Savolainen S, Joensuu H: Boron neutron capture therapy in the treatment of locally recurred head-and-neck cancer: final analysis of a phase I/II trial. Int J Radiat Oncol Biol Phys 82: e67-e75, 2012

8) Kato I, Ono K, Sakurai Y, Ohmae M, Maruhashi A, Imahori Y, Kirihata M, Nakazawa M, Yura Y: Effectiveness of BNCT for recurrent head and neck malignancies. Appl Radiat Isot 61: 1069-1073, 2004

9) Kato I, Fujita Y, Maruhashi A, Kumada H, Ohmae M, Kirihata M, Imahori Y, Suzuki M, Sakrai Y, Sumi T, Iwai S, Nakazawa M, Murata I, Miyamaru H, Ono $\mathrm{K}$ : Effectiveness of boron neutron capture therapy for recurrent head and neck malignancies. Appl Radiat Isot 67: S37-S42, 2009

10) Farr LE, Sweet WH, Locksley HB, Robertson JS: Neutron capture therapy of gliomas using boron. Trans Am Neurol Assoc 13: 110-113, 1954

11) Asbury AK, Ojemann RG, Nielsen SL, Sweet WH: Neuropathologic study of fourteen cases of malignant brain tumor treated by boron-10 slow neutron capture radiation. J Neuropathol Exp Neurol 31: 278-303, 1972

12) Soloway AH, Tjarks W, Barnum BA, Rong FG, Barth RF, Codogni IM, Wilson JG: The chemistry of neutron capture therapy. Chem Rev 98: 1515-1562, 1998

13) Ono K, Masunaga SI, Kinashi Y, Takagaki M, Akaboshi M, Kobayashi T, Akuta K: Radiobiological evidence suggesting heterogeneous microdistribution of boron compounds in tumors: its relation to quiescent cell population and tumor cure in neutron capture therapy. Int J Radiat Oncol Biol Phys 34: 1081-1086, 1996

14) Imahori $Y$, Ueda S, Ohmori $Y$, Sakae K, Kusuki T, Kobayashi T, Takagaki M, Ono K, Ido T, Fujii R: Positron emission tomography-based boron neutron capture therapy using boronophenylalanine for highgrade gliomas: part I. Clin Cancer Res 4: 1825-1832, 1998

15) Imahori Y, Ueda S, Ohmori Y, Sakae K, Kusuki T, Kobayashi T, Takagaki M, Ono K, Ido T, Fujii R: Positron emission tomography-based boron neutron capture therapy using boronophenylalanine for high-grade gliomas: part II. Clin Cancer Res 4: 1833-1841, 1998

16) Takahashi Y, Imahori Y, Mineura K: Prognostic and therapeutic indicator of fluoroboronophenylalanine positron emission tomography in patients with gliomas. Clin Cancer Res 9: 5888-5895, 2003

17) Kawabata S, Miyatake S, Kajimoto Y, Kuroda Y, Kuroiwa T, Imahori Y, Kirihata M, Sakurai Y, Kobayashi T, Ono K: The early successful treatment of glioblastoma patients with modified boron neutron capture therapy. Report of two cases. J Neurooncol 65: 159-165, 2003

18) Miyatake S, Kawabata S, Kajimoto Y, Aoki A, Yokoyama K, Yamada M, Kuroiwa T, Tsuji M, Imahori Y, Kirihata M, Sakurai Y, Masunaga S, Nagata K, Maruhashi A, Ono K: Modified boron neutron capture therapy for malignant gliomas performed using epithermal neutron and two boron compounds with different accumulation mechanisms: an efficacy study based on findings on neuroimages. J Neurosurg 103: 1000-1009, 2005

19) Kawabata S, Hiramatsu R, Kuroiwa T, Ono K, Miyatake S: Boron neutron capture therapy for recurrent highgrade meningiomas. J Neurosurg 119: 837-844, 2013

20) Miyatake S, Kawabata S, Yokoyama K, Kuroiwa T, Michiue H, Sakurai Y, Kumada H, Suzuki M, Maruhashi A, Kirihata M, Ono K: Survival benefit of boron neutron capture therapy for recurrent malignant gliomas. J Neurooncol 91: 199-206, 2009

21) Carson KA, Grossman SA, Fisher JD, Shaw EG: Prognostic factors for survival in adult patients with recurrent glioma enrolled onto the new approaches to brain tumor therapy CNS consortium phase I and II clinical trials. J Clin Oncol 25: 2601-2606, 2007

22) Furuse M, Kawabata S, Kuroiwa T, Miyatake S: Repeated treatments with bevacizumab for recurrent radiation necrosis in patients with malignant brain tumors: a report of 2 cases. J Neurooncol 102: 471-475, 2011

23) Levin VA, Bidaut L, Hou P, Kumar AJ, Wefel JS, Bekele BN, Grewal J, Prabhu S, Loghin M, Gilbert MR, Jackson EF: Randomized double-blind placebocontrolled trial of bevacizumab therapy for radiation necrosis of the central nervous system. Int J Radiat Oncol Biol Phys 79: 1487-1495, 2011

24) Miyatake S, Furuse M, Kawabata S, Maruyama T, Kumabe T, Kuroiwa T, Ono K: Bevacizumab treatment of symptomatic pseudoprogression after boron neutron capture therapy for recurrent malignant gliomas. Report of 2 cases. Neuro-oncology 15: 650-655, 2013

25) Miyatake S, Kawabata S, Hiramatsu R, Furuse M, Kuroiwa T, Suzuki M: Boron neutron capture therapy with bevacizumab may prolong the survival of recurrent malignant glioma patients: four cases. Radiat Oncol 9: 6, 2014

26) Furuse M, Nonoguchi N, Kuroiwa T, Miyamoto S, Arakawa Y, Shinoda J, Miwa K, Iuchi T, Tsuboi 
K, Houkin K, Terasaka S, Tabei Y, Nakamura H, Nagane M, Sugiyama K, Terasaki M, Abe T, Narita Y, Saito N, Mukasa A, Ogasawara K, Beppu T, Kumabe T, Nariai T, Tsuyuguchi N, Nakatani E, Kurisu S, Nakagawa Y, Miyatake SI: A prospective multicenter single-arm clinical trial of bevacizumab for patients with surgically untreatable, symptomatic brain radiation necrosis. Neuro-Oncology Practice [in press]

27) Nakagawa Y, Hatanaka H: Boron neutron capture therapy. Clinical brain tumor studies. J Neurooncol 33: 105-115, 1997

28) Laramore GE, Spence AM: Boron neutron capture therapy (BNCT) for high-grade gliomas of the brain: a cautionary note. Int J Radiat Oncol Biol Phys 36: 241-246, 1996

29) Curran WJ Jr, Scott CB, Horton J, Nelson JS, Weinstein AS, Fischbach AJ, Chang CH, Rotman M, Asbell SO, Krisch RE: Recursive partitioning analysis of prognostic factors in three Radiation Therapy Oncology Group malignant glioma trials. J Natl Cancer Inst 85: 704-710, 1993

30) Busse PM, Harling OK, Palmer MR, Kiger WS, Kaplan J, Kaplan I, Chuang CF, Goorley JT, Riley KJ, Newton TH, Santa Cruz GA, Lu XQ, Zamenhof RG: A critical examination of the results from the Harvard-MIT NCT program phase I clinical trial of neutron capture therapy for intracranial disease. J Neurooncol 62: 111-121, 2003

31) Diaz AZ: Assessment of the results from the phase I/II boron neutron capture therapy trials at the Brookhaven National Laboratory from a clinician's point of view. J Neurooncol 62: 101-109, 2003

32) Henriksson R, Capala J, Michanek A, Lindahl SA, Salford LG, Franzén L, Blomquist E, Westlin JE, Bergenheim AT; Swedish Brain Tumour Study Group: Boron neutron capture therapy (BNCT) for glioblastoma multiforme: a phase II study evaluating a prolonged high-dose of boronophenylalanine (BPA). Radiother Oncol 88: 183-191, 2008

33) Joensuu H, Kankaanranta L, Seppälä T, Auterinen I, Kallio M, Kulvik M, Laakso J, Vähätalo J, Kortesniemi M, Kotiluoto P, Serén T, Karila J, Brander A, Järviluoma E, Ryynänen P, Paetau A, Ruokonen I, Minn H, Tenhunen M, Jääskeläinen J, Färkkilä M, Savolainen S: Boron neutron capture therapy of brain tumors: clinical trials at the finnish facility using boronophenylalanine. J Neurooncol 62: 123-134, 2003

34) Kawabata S, Miyatake S, Kuroiwa T, Yokoyama K, Doi A, Iida K, Miyata S, Nonoguchi N, Michiue $\mathrm{H}$, Takahashi $\mathrm{M}$, Inomata $\mathrm{T}$, Imahori Y, Kirihata M, Sakurai Y, Maruhashi A, Kumada H, Ono K: Boron neutron capture therapy for newly diagnosed glioblastoma. J Radiat Res 50: 51-60, 2009

35) Kawabata S, Miyatake S, Hiramatsu R, Hirota Y, Miyata S, Takekita Y, Kuroiwa T, Kirihata M, Sakurai Y, Maruhashi A, Ono K: Phase II clinical study of boron neutron capture therapy combined with $\mathrm{X}$-ray radiotherapy/temozolomide in patients with newly diagnosed glioblastoma multiforme-study design and current status report. Appl Radiat Isot 69: 1796-1799, 2011

36) Yamamoto T, Nakai K, Kageji T, Kumada H, Endo K, Matsuda M, Shibata Y, Matsumura A: Boron neutron capture therapy for newly diagnosed glioblastoma. Radiother Oncol 91: 80-84, 2009

37) Jääskeläinen J, Haltia $M$, Servo A: Atypical and anaplastic meningiomas: radiology, surgery, radiotherapy, and outcome. Surg Neurol 25: 233-242, 1986

38) Palma L, Celli P, Franco C, Cervoni L, Cantore G: Long-term prognosis for atypical and malignant meningiomas: a study of 71 surgical cases. J Neurosurg 86: 793-800, 1997

39) Chamberlain MC: The role of chemotherapy and targeted therapy in the treatment of intracranial meningioma. Curr Opin Oncol 24: 666-671, 2012

40) Tamura Y, Miyatake S, Nonoguchi N, Miyata S, Yokoyama K, Doi A, Kuroiwa T, Asada M, Tanabe H, Ono K: Boron neutron capture therapy for recurrent malignant meningioma. Case report. J Neurosurg 105: 898-903, 2006

41) Miyatake S, Tamura Y, Kawabata S, Iida K, Kuroiwa T, Ono K: Boron neutron capture therapy for malignant tumors related to meningiomas. Neurosurgery 61: 82-90; discussion 90-91, 2007

42) Tanaka H, Sakurai Y, Suzuki M, Masunaga S, Mitsumoto T, Fujita K, Kashino G, Kinashi Y, Liu Y, Takada M, Ono K, Maruhashi A: Experimental verification of beam characteristics for cyclotronbased epithermal neutron source (C-BENS). Appl Radiat Isot 69: 1642-1645, 2011

43) Tanaka H, Sakurai Y, Suzuki M, Masunaga S, Mitsumoto T, Kinashi Y, Kondo N, Narabayashi M, Nakagawa Y, Watanabe T, Fujimoto N, Maruhashi A, Ono K: Evaluation of thermal neutron irradiation field using a cyclotron-based neutron source for alpha autoradiography. Appl Radiat Isot 88: 153-156, 2014

44) Bregadze VI, Sivaev IB, Lobanova IA, Titeev RA, Brittal DI, Grin MA, Mironov AF: Conjugates of boron clusters with derivatives of natural chlorin and bacteriochlorin. Appl Radiat Isot 67: S101-S104, 2009

45) Altieri S, Balzi M, Bortolussi S, Bruschi P, Ciani L, Clerici AM, Faraoni P, Ferrari C, Gadan MA, Panza L, Pietrangeli D, Ricciardi G, Ristori S: Carborane derivatives loaded into liposomes as efficient delivery systems for boron neutron capture therapy. J Med Chem 52: 7829-7835, 2009

46) Li T, Hamdi J, Hawthorne MF: Unilamellar liposomes with enhanced boron content. Bioconjug Chem 17: 15-20, 2006

47) Crossley EL, Ziolkowski EJ, Coderre JA, Rendina LM: Boronated DNA-binding compounds as potential agents for boron neutron capture therapy. Mini Rev Med Chem 7: 303-313, 2007

48) Doi A, Kawabata S, Iida K, Yokoyama K, Kajimoto Y, Kuroiwa T, Shirakawa T, Kirihata M, Kasaoka S, Maruyama K, Kumada H, Sakurai Y, Masunaga S, Ono K, Miyatake S: Tumor-specific targeting of sodium 
borocaptate (BSH) to malignant glioma by transferrinPEG liposomes: a modality for boron neutron capture therapy. J Neurooncol 87: 287-294, 2008

49) Ito Y, Kimura Y, Shimahara T, Ariyoshi Y, Shimahara M, Miyatake S, Kawabata S, Kasaoka S, Ono K: Disposition of TF-PEG-liposome-BSH in tumorbearing mice. Appl Radiat Isot 67: S109-S110, 2009

50) Renner MW, Miura M, Easson MW, Vicente MG: Recent progress in the syntheses and biological evaluation of boronated porphyrins for boron neutron-capture therapy. Anticancer Agents Med Chem 6: 145-157, 2006

51) Hiramatsu R, Kawabata S, Miyatake S, Kuroiwa T, Easson MW, Vicente MG: Application of a novel boronated porphyrin $\left(\mathrm{H}_{2} \mathrm{OCP}\right)$ as a dual sensitizer for both PDT and BNCT. Lasers Surg Med 43: 52-58, 2011

52) Hiramatsu R, Kawabata S, Tanaka H, Sakurai Y, Suzuki M, Ono K, Miyatake S, Kuroiwa T, Hao E, Vicente MG: Tetrakis(p-carboranylthio-tetrafluorophenyl)chlorin (TPFC): application for photodynamic therapy and boron neutron capture therapy. J Pharm Sci 104: 962-970, 2015

53) Capala J, Barth RF, Bendayan M, Lauzon M, Adams DM, Soloway AH, Fenstermaker RA, Carlsson J: Boronated epidermal growth factor as a potential targeting agent for boron neutron capture therapy of brain tumors. Bioconjug Chem 7: 7-15, 1996

54) Backer MV, Gaynutdinov TI, Patel V, Bandyopadhyaya AK, Thirumamagal BT, Tjarks W, Barth RF, Claffey K, Backer JM: Vascular endothelial growth factor selectively targets boronated dendrimers to tumor vasculature. Mol Cancer Ther 4: 1423-1429, 2005

55) Yang W, Barth RF, Wu G, Kawabata S, Sferra TJ, Bandyopadhyaya AK, Tjarks W, Ferketich AK, Moeschberger ML, Binns PJ, Riley KJ, Coderre JA, Ciesielski MJ, Fenstermaker RA, Wikstrand CJ: Molecular targeting and treatment of EGFRvIII-positive gliomas using boronated monoclonal antibody L8A4. Clin Cancer Res 12: 3792-3802, 2006

56) Wu G, Yang W, Barth RF, Kawabata S, Swindall M, Bandyopadhyaya AK, Tjarks W, Khorsandi B, Blue TE, Ferketich AK, Yang M, Christoforidis GA, Sferra TJ, Binns PJ, Riley KJ, Ciesielski MJ, Fenstermaker RA: Molecular targeting and treatment of an epidermal growth factor receptor-positive glioma using boronated cetuximab. Clin Cancer Res 13: 1260-1268, 2007

57) Yang W, Wu G, Barth RF, Swindall MR, Bandyopadhyaya AK, Tjarks W, Tordoff K, Moeschberger M, Sferra TJ, Binns PJ, Riley KJ, Ciesielski MJ, Fenstermaker RA, Wikstrand CJ: Molecular targeting and treatment of composite EGFR and EGFRvIII-positive gliomas using boronated monoclonal antibodies. Clin Cancer Res 14: 883-891, 2008

58) Yang W, Barth RF, Wu G, Huo T, Tjarks W, Ciesielski M, Fenstermaker RA, Ross BD, Wikstrand CJ, Riley KJ, Binns PJ: Convection enhanced delivery of boronated EGF as a molecular targeting agent for neutron capture therapy of brain tumors. J Neurooncol 95: 355-365, 2009

59) Yang W, Barth RF, Wu G, Tjarks W, Binns P, Riley K: Boron neutron capture therapy of EGFR or EGFRvIII positive gliomas using either boronated monoclonal antibodies or epidermal growth factor as molecular targeting agents. Appl Radiat Isot 67: S328-S331, 2009

60) Michiue H, Sakurai Y, Kondo N, Kitamatsu M, Bin F, Nakajima K, Hirota Y, Kawabata S, Nishiki T, Ohmori I, Tomizawa K, Miyatake S, Ono K, Matsui $\mathrm{H}$ : The acceleration of boron neutron capture therapy using multi-linked mercaptoundecahydrododecaborate (BSH) fused cell-penetrating peptide. Biomaterials 35: 3396-3405, 2014

61) Imahori $Y$, Ueda S, Ohmori Y, Kusuki T, Ono K, Fujii R, Ido T: Fluorine-18-labeled fluoroboronophenylalanine PET in patients with glioma. J Nucl Med 39: 325-333, 1998

62) Miyashita M, Miyatake S, Imahori Y, Yokoyama K, Kawabata S, Kajimoto Y, Shibata MA, Otsuki Y, Kirihata M, Ono K, Kuroiwa T: Evaluation of fluoride-labeled boronophenylalanine-PET imaging for the study of radiation effects in patients with glioblastomas. J Neurooncol 89: 239-246, 2008

Address reprint requests to: Shin-Ichi Miyatake, MD, $\mathrm{PhD}$, Cancer Center, Osaka Medical College, 2-7 DaigakuMachi, Takatsuki, Osaka 569-8686, Japan.

e-mail: neu070@osaka-med.ac.jp 